\title{
Estado e Mercado: adversários ou aliados no processo de implementação da Política Nacional de Alimentação e Nutrição? Elementos para um debate sobre medidas de regulamentação
}

State and Market: adversaries or allies in the implementation of the National Food and Nutrition Policy? Some reflections on regulation measures

\author{
Anelise Rizzolo de Oliveira Pinheiro \\ Nutricionista, Sanitarista, Mestre em Saúde Pública (UFSC), Dou- \\ toranda em Política Social / SER/UNB; Professora Visitante do De- \\ partamento de Nutrição da Faculdade de Saúde da Universidade \\ de Brasília e Pesquisadora Associada do Observatório de Políticas \\ em Segurança Alimentar e Nutrição/NP3/ UNB. \\ Endereço: Universidade de Brasília, Campus Universitário Darcy \\ Ribeiro, Núcleo de Medicina Tropical e Nutrição, Observatório de \\ Politicas de Segurança Alimentar e Nutrição, sala 9 c, Asa Norte, \\ CEP 70910-900, Brasilia, DF, Brasil. \\ E-mail: aneropinळyahoo.com.br \\ Denise Bomtempo Birche de Carvalho \\ Assistente Social, Doutora em Sociologia pela Universidade de Pa- \\ ris/França; Professora Adjunta do Departamento de Serviço Social. \\ Endereço: Universidade de Brasilia, Campus Universitário Darcy \\ Ribeiro, Instituto de Ciências Humanas, Departamento de Serviço \\ Social/ SER, Asa Norte, CEP 70910-900, Brasilia, DF, Brasil. \\ E-mail: bircheœterra.com.br
}

\section{Resumo}

A alimentação e a nutrição constituem requisitos básicos para a promoção e a proteção da saúde, possibilitando a afirmação plena do potencial de crescimento e desenvolvimento humano, com qualidade de vida e cidadania. As mudanças na relação do Estado, sociedade civil e mercado têm trazido uma série de conseqüências sociais adversas, especialmente no campo da saúde e nutrição. Este artigo tem como propósito provocar algumas reflexões relativas à necessidade de pactuação entre Estado, sociedade e mercado para a efetivação de medidas capazes de atuar positivamente no controle da obesidade e conseqüentemente melhorar as condições de saúde e nutrição da população brasileira. Apresenta uma breve descrição de contexto histórico sobre política social no Brasil e seus reflexos específicos na temática de alimentação e nutrição; identifica aspectos políticos principais para uma análise das diretrizes da Política Nacional de Alimentação e Nutrição; destaca o fortalecimento de medidas de regulamentação como estratégia de enfrentamento do problema de excesso de peso / obesidade na sociedade, identificando suas raízes a partir do modo de viver urbano, globalizado e neoliberal das ultimas décadas, e, por fim, sugere elementos para enriquecer esse debate. Medidas de regulamentação parecem poder influenciar positivamente nas ações de promoção da saúde, pois estabelecem limites e um conjunto de critérios para mediar as relações entre sociedade e mercado, além de refletir o apoio e a pro- 
teção da saúde do cidadão como objetivo principal do Estado nesse processo.

Palavras-chave: Política Social; Neoliberalismo; Alimentação e Nutrição; Promoção da Saúde; Medidas de Regulamentação.

\section{Abstract}

Food and nutrition constitute basic requirements for health promotion and protection, enabling the full expression of the human potential for growth and development, with quality of life and citizenship. Changes in the relationship between State, Civil Society, and the Market have brought several adverse social consequences, particularly in the health and nutrition field. This article intends to stimulate some reflections related to the need of an agreement between State, Civil Society and the Market for the accomplishment of measures that are able to contribute to obesity control and, as a consequence, to improve health and nutrition conditions of the Brazilian population. The article also presents a brief description of the historical context of social policies in Brazil and their specific consequences to food and nutrition matters; it identifies the main political aspects to analyze guidelines of the National Food and Nutrition Policy; it emphasizes the strengthening of regulation measures as a strategy to face the problem of excess of weight / obesity in society, identifying its roots in the urban, 'global' and neoliberal way of life of the last decades and, as a conclusion, it suggests more elements to enrich this debate. Regulation Measures seem to have a positive influence on health promotion actions by setting up the boundaries and criteria to mediate the relationship between Civil Society and the Market, besides reflecting the support and protection of the citizen's health as the main purpose of the State in this process.

Keywords: Social Policies; Neoliberalism; Food and Nutrition; Health Promotion; Regulation Measures.

\section{Introdução}

A alimentação e a nutrição constituem requisitos básicos para a promoção e a proteção da saúde, possibilitando a afirmação plena do potencial de crescimento e desenvolvimento humano, com qualidade de vida e cidadania (Brasil, 1999).

A história das políticas de alimentação e nutrição, no Brasil, se inicia a partir da década de 1940 por meio de algumas iniciativas do Estado na era Vargas. A ação precursora foi a criação dos Serviços de Alimentação e Previdência Social (SAPS), onde o Estado assume a tarefa de melhorar os níveis de alimentação e nutrição, ao invés de partilhar com o setor privado a tarefa de dar condições à garantia de uma alimentação adequada aos seus trabalhadores (Pelliano, 1998).

A criação do Instituto Nacional de Alimentação e Nutrição - INAN, em 1972, é um marco para as iniciativas públicas nesse campo, pois instituiu um conjunto de programas direcionados a populações em situação de insuficiência alimentar e a grupos específicos considerados de risco, como gestantes, crianças e nutrizes, além dos trabalhadores do mercado formal de emprego (Burlandy, 2003).

No conjunto de programas sociais que eram voltados para os segmentos mais carentes, os programas de alimentação e nutrição são exemplos paradigmáticos do padrão histórico de atuação do Estado no combate à pobreza no país, e o INAN era, em parte, a representação desse padrão. Nesta análise, o INAN, no setor saúde, acabava refletindo os problemas gerais encontrados na implementação das políticas sociais no Brasil, como seletividade e ineficiência; fusões de programas e superposição de clientelas; expansão de cobertura à custa da quantidade e qualidade dos alimentos distribuídos; a centralização no nível federal da compra de alimentos; a inadequação dos produtos formulados aos hábitos alimentares da população; o elevado índice de evasão da clientela atendida; e as dificuldades de captação de novos beneficiários (Pessanha, 2002).

Em meio a essas contradições, a constituição Federal de 1988, em formulação no período, buscou no capítulo da seguridade social seu pilar mais sólido de sustentação na área social. Influenciado pelo clima político-social da abertura e com o discurso de que era preciso "resgatar a enorme dívida social herdada 
do regime militar", o Congresso Nacional procurou garantir direitos básicos e universais de cidadania inscrevendo o direito à saúde, assistência social e previdência em um capítulo específico da Constituição: o capítulo da Seguridade Social (Mozart, 2005, p. 1).

É importante destacar que a temática da alimentação e nutrição, no campo das políticas públicas, é acolhida pelo setor saúde e tem na lei Orgânica do Sistema Único de Saúde ( $\mathrm{n}^{\circ}$. 8o8o) o respaldo legal necessário para se "fixar" e propor ações nesse sentido. Contudo, projetos, programas e ações relativos à assistência social continuaram a realizar práticas de distribuição de alimentos à população de baixa renda.

Após a extinção do INAN (em 1997), sob a luz do início da ascensão do modelo neoliberal, com o desmantelamento de instituições públicas e fortes denúncias de corrupção, um conjunto de técnicos, intelectuais orgânicos e acadêmicos, assumiram a construção da PNAN como um caminho possível de resistência e valorização desta temática no Ministério da Saúde.

Assim, em 1999, após um processo participativo de formulação, é homologada a Política Nacional de Alimentação e Nutrição (PNAN) junto ao Conselho Nacional de Saúde, após as devidas pactuações nas instâncias colegiadas que compõem o SUS. A PNAN assumiu como fundamentos o entendimento da alimentação saudável enquanto um direito humano, e a necessidade de articulação e da busca da garantia da segurança alimentar e nutricional. Desta forma, pressupõe-se que só haverá condições de pleno exercício do direito humano a alimentação adequada através de medidas institucionais que visem à segurança alimentar e nutricional.

Segurança Alimentar e Nutricional (SAN) é a garantia, a todos, de condições de acesso a alimentos básicos de qualidade, em quantidade suficiente, de modo permanente e sem comprometer a outras necessidades básicas como saúde, educação, moradia, trabalho, lazer etc., com base em práticas alimentares que contribuem, assim, para uma existência digna em um contexto de desenvolvimento integral da pessoa humana (CONSEA, 2004). Entende-se que, na mesma medida em que a alimentação saudável é um direito humano, é um dever do Estado criar condições de proteção, promoção e provimento desse direito através da SAN, como eixo articulador do desenvolvimento social, político e econômico do país.
Este artigo tem como propósito provocar algumas reflexões relativas à necessidade de pactuação entre Estado, sociedade e mercado para a efetivação de medidas capazes de atuar positivamente no controle da obesidade e conseqüente melhoria das condições de saúde e nutrição da população brasileira. Apresenta uma sumária descrição de contexto histórico sobre política social no Brasil e seus reflexos específicos na temática de alimentação e nutrição; identifica aspectos políticos principais para uma análise sobre as diretrizes da Política Nacional de Alimentação e Nutrição (considerando o cenário epidemiológico atual). Além disso, destaca o fortalecimento de medidas de regulamentação como estratégia de enfrentamento do problema de excesso de peso / obesidade na sociedade, identificando suas raízes a partir do modo de viver urbano, globalizado e neoliberal das ultimas décadas e, por fim, sugere elementos para enriquecer esse debate.

\section{Apresentando a Política Nacional de Alimentação e Nutrição: uma política social}

A PNAN, além de fundamentos, baseia suas ações em sete diretrizes. Sendo elas: o estímulo às ações intersetoriais com vistas ao acesso universal aos alimentos; a garantia da segurança e da qualidade dos alimentos e da prestação de serviços neste contexto; o monitoramento da situação alimentar e nutricional; a promoção de práticas alimentares e estilos de vida saudáveis; a prevenção e controle dos distúrbios nutricionais e de doenças associadas à alimentação e nutrição; a promoção do desenvolvimento de linhas de investigação e o desenvolvimento e capacitação de recursos humanos (Brasil, 1999).

A PNAN é uma política social inserida no gênero de políticas públicas. Neste particular, é importante esclarecer que o termo política social, especialmente no Brasil, pode ter diferentes nuances. Essa política tem uma identidade própria e refere-se a "um programa de ação que visa, mediante esforço organizado, atender necessidades sociais cuja resolução ultrapassa a iniciativa privada, individual e espontânea, e requer decisão coletiva regida e amparada por leis impessoais e objetivas, garantidoras de direitos" (Pereira, 1994, p.1). Políticas agrárias, econômicas, ambientais 
etc. também são integrantes do gênero de políticas públicas, e para a alimentação e nutrição, são fundamentais. Essas políticas devem compor um elenco estratégico de ações, uma vez que para o consumo saudável é necessária uma trajetória que contemple toda cadeia do processo produtivo: produção e abastecimento, comercialização, acesso ao alimento até o consumo e a plena utilização biológica.

Em termos conceituais, políticas públicas são "linhas de ação coletiva que concretizam direitos sociais declarados e garantidos por lei", ou seja, são respostas do Estado às demandas que emergem da sociedade, sendo a expressão do compromisso público de atuação em uma determinada área em longo prazo (Pereira, 1994, p 12). Para Demo (2002), as política sociais precisam ser estratégicas para contemplar todos os componentes sociais, políticos, econômicos e culturais inerentes a ela, pois precisam alcançar seu objetivo principal que é o de emancipação da sociedade. Devem ter a inserção no mercado e a constituição da qualidade política como ferramentas capazes de exercer controle democrático efetivo. O cunho político (politicidade) da política social é central nesse debate, por isso o "saber pensar" passa a ser o tênue fio construtor deste processo de provocação de cidadania.

Nesse contexto de política social, o modelo do welfare state é a grande referência enquanto matriz de sustentação da questão social no modelo capitalista no mundo. Após a crise econômica de 1929 (a Grande Depressão), com a queda da Bolsa de Valores de Nova York, colocou-se em dúvida a consistência das bases liberais capitalistas que defendiam rigorosa liberdade, ou seja, a não interferência estatal para indivíduos e empresas, especialmente no que diz respeito à atividade produtiva e às relações capital-trabalho, ocorrendo uma intensificação da questão social e o desenvolvimento do capitalismo monopolista (Pereira, 1999).

Nos países desenvolvidos, como França, Alemanha e Inglaterra, estas duas questões foram determinantes para o estabelecimento das novas relações entre o Estado, o capital e o trabalho. As elites econômicas passaram a admitir os limites do mercado como reguladores "naturais" das relações sociais. Nesse sentido, as políticas sociais passaram a ser entendidas como estratégias de intervenção e regulação do Estado no que diz respeito à questão social. 0 Estado social assume o papel de mediador civilizador que tem poderes políticos de interferência nestas relações sociais, é, portanto, um sistema de proteção que expressa a formalização institucional dos direitos sociais adquiridos (Pereira, 1999; Cunha e Cunha, 2003).

No Brasil, a política social teve um desenvolvimento lento, débil, tardio e reducionista. Primeiramente, a questão social foi tratada como questão de polícia. Um bom exemplo dessa estratégia foram os modelos campanhistas higienistas liderados por Oswaldo Cruz, no início do século XIX, que instituiu a polícia médica (o filme "A revolta da Vacina" ilustra muito bem este momento histórico). Num segundo momento, na década de 30, o governo de Getúlio Vargas elabora um complexo sistema de gestão e regulação dos conflitos sociais e a Consolidação das Leis do Trabalho - CLT (baseada no modelo fascista italiano) passa a regular as relações entre os que compram e os que vendem a força de trabalho (Silva, 1999). A estratégia conservadora segue este relato histórico no período de ditadura (1964 - 1985) com ênfase na regressividade dos mecanismos de financiamento, na centralização dos processos decisórios, na privatização do espaço público, na expansão de cobertura dos bens e serviços e no reduzido caráter re-distributivo. No período de 1985 - 1989, a estratégia reformista passa a prevalecer com características como: o crescimento sustentado; a ampliação do emprego, o aumento do salário real, a melhor distribuição de renda, a reforma agrária, o seguro desemprego, a revisão da legislação trabalhista e sindical, a descentralização político - administrativa, a participação e controle social, a redefinição do padrão progressivo de financiamento das políticas sociais, a universalização do acesso e a ampliação do impacto redistributivo (Fagnani, 1999).

Esse período reformista é o cenário de aprovação da constituição “Cidadã” brasileira (1988) que institui o Sistema Único de Saúde (SUS) e ancora a posterior elaboração da PNAN (além de inúmeras outras políticas sociais).

\footnotetext{
1 Teoria que se pautava numa redefinição do papel do Estado. Criada pelo economista britânico John Maynard Keynes, atribuía ao Estado a função de "impulsionar e promover" o desenvolvimento econômico e social, partindo da premissa de que o setor privado não é capaz, por si só, de garantir a estabilidade da economia (Pereira,1999).
} 
Para efeito desta análise, podemos fazer uma categorização de macro-objetivos norteadores das diretrizes da PNAN em dois grandes eixos: o primeiro que reúne um conjunto de medidas e propostas voltadas para os serviços de saúde, tanto para fortalecer e capacitar os profissionais de saúde na temática da alimentação saudável, quanto para prevenir e controlar carências nutricionais no Brasil, como anemia ferropriva e deficiência de vitamina A. Portanto, busca incorporar às práticas cotidianas dos serviços de saúde o componente nutricional e, assim, qualificar a atenção à saúde; o segundo conjuga esforços para abrir um diálogo para "fora do setor saúde", na tentativa de fomentar a formulação de políticas públicas para criação de ambientes saudáveis e de processos de educação em saúde, fortalecer a autonomia decisória dos sujeitos e a tomada de consciência da população sobre suas reais condições nutricionais. Para tal, tem a intersetorialidade como eixo central e chama a sociedade civil e o mercado para este debate.

Neste conjunto, a estratégia de instituição de medidas de regulamentação está descrita na PNAN e inserida na diretriz de promoção de práticas alimentares e estilos de vida saudáveis, da seguinte forma: "importante também será a adoção de medidas voltadas ao disciplinamento da publicidade e práticas de marketing de produtos alimentícios industrializados, sobretudo em parceria com as entidades representativas da área de propaganda, com empresas de comunicação, com entidades da sociedade civil e do setor produtivo" (Brasil, 1999, p. 22).

\section{Cenário Epidemiológico e Político - Social Atual}

O cenário epidemiológico nacional e internacional vem apontando o crescimento importante da morbimortalidade geral por doenças crônicas não-transmissíveis (DCNT). As mudanças ocorridas nos processos de organização das sociedades industriais (industrialização e globalização), que ao longo das ultimas décadas tornaram-se eminentemente urbanas, com maior expectativa de vida e melhoria do acesso a tecnologias em geral, trouxeram como um de seus efeitos perversos o aumento alarmante da obesidade e o excesso de peso nas populações.

Entende-se o neoliberalismo como a retomada de alguns princípios do capitalismo liberal do século XIX. Significa a reação teórica e política veemente contra o Estado intervencionista e de bem-estar que se instalou em alguns países no pós-guerra, influenciado pela Revolução Soviética de 1917 (Anderson, 1995). É a busca de uma política econômica que vigore sem qualquer limitação dos mecanismos do mercado (Pires e Reis, 1999).

De acordo com Pereira (2002), o neoliberalismo é uma matriz ideológica que defende a idéia de que o mercado, e não o Estado, deveria ser o único alocador de salários e capital. Defende a desregulamentação total, a derrubada das barreiras comerciais e a livre circulação de bens, de trabalho e de capital. A política neoliberal prevê uma ampla desregulamentação e liberalização das regras de comércio e alocação de capitais internacionais, a quebra de barreiras e a abertura das bolsas e de todos os setores da economia às multinacionais.

Tem como carcterísticas principais: os ideais de liberdade e autonomia individual sobre os de igualdade e justiça social; advoga a reconstituição e revigoramento da sociedade civil como um contraponto aos supostos poderes excessivos do Estado; prega a revitalização das instituições voluntárias e de sua ativa participação no processo de provisão social, num contexto de responsabilidades compartilhadas em que o estado, o mercado e a sociedade seriam parceiros em igualdade de condições.

Uma economia de mercado é um sistema econômico controlado, regulado e dirigido apenas por mercados onde a ordem de produção e a distribuição dos bens é "refém" desse sistema. O máximo de ganhos monetários é o grande objetivo a ser perseguido pela sociedade. Para Polanyi (200o, p. 93), a adoção do modelo de economia de mercado nas sociedades a partir do século XIX transformou o trabalho e a terra em mercadorias fictícias (o mercantilismo até então dispunha de formas de intervenção estatal e proteção para estes dois elementos básicos da produção). Afirma que "a inclusão do trabalho e da terra no mecanismo de mercado significa subordinar a substância da própria sociedade - da própria vida - às leis de mercado".

Ele sustenta a tese de que para a manutenção da economia de mercado foi preciso criar mercado para todos os elementos da indústria. Assim, cada um dos 
elementos é organizado em um grupo de oferta e de demanda (mercadoria - mercado = compra e venda). $\mathrm{Na}$ sociedade atual, tanto o alimento (ou comida) quanto o corpo também são vistos como elementos de venda para este mercado. Para Lefèvre (1999), a dominância do mercado financeiro na vida da sociedade em geral é tão grande que acaba submetendo a saúde dos indivíduos ao consumo e, desta forma, as pessoas buscam produtos que lhes possibilitem atingir um padrão de boa saúde que é insistentemente veiculado pela mídia, a qual, por sua vez, obedece a interesses hegemônicos, que tratam também a saúde como uma mercadoria.

No contexto neoliberal, a política social passa a ser vista como paternalismo, como geradora de desequilíbrio, como geradora de algo que deve ser acessado via mercado e não como um direito social. Daí a tendência de dês-responsabilização do Estado e dês-investimentos das ações que configurem proteção social pelo Estado, o que paulatinamente vai desenhando o Estado mínimo para a população trabalhadora e o Estado máximo para o capital (Berlinguer, 2002). Para Berlinguer (2002), esse quadro fomenta a desregulamentação dos direitos sociais, de garantias fiscais ao capital e da política de privatização, sem falar do pacto da fuga fiscal "despercebida" que viabiliza os super lucros e acumulação do capital. Por isso, atualmente as políticas sociais, como a PNAN, tem a grande orientação de focalização das ações.

Apesar de ser voltada para o conjunto da sociedade brasileira, os principais programas e ações da PNAN são focalizados e seletivos. São eles: o Programa Nacional de Controle da Deficiência de Vitamina A, o Programa de controle de Anemia Ferropriva e o Sistema de Vigilância Alimentar e Nutricional que tem ações de parceria com o Bolsa Família². Todos voltados para grupos específicos: crianças, nutrizes e gestantes de famílias beneficiárias dos programas de transferência de renda.
As idéias neoliberais encontram no processo denominado de globalização terreno fértil para proliferarem e se expandirem no mundo todo. A globalização é caracterizada como um processo contemporâneo ancorado nas novas formas de tecnologia, na rapidez do trânsito de informações, técnicas, produtos, padrões, estilos de vida e ideologias. A globalização, tal como entendida pela maioria dos que a estudam, acaba por romper quase todas as barreiras dos países, das cidades e dos continentes, estabelecendo, pelo menos em princípio, padrões mundiais de consumo e de idéias. Esse processo tende a descaracterizar e uniformizar os padrões locais. No contexto da alimentação, reflete-se como uma padronização de consumo, de valores ocidentais baseados em símbolos e produtos (incluindo a formatação de paladares e preparações como os fast foods) cada vez mais supérfluos e simplesmente adequados à lógica do consumismo exacerbado (Setti, 2004).

$\mathrm{Na}$ atualidade, o fenômeno da globalização acentuou as exigências de competitividade e eficiência das economias. Isso tem ocasionado importantes alterações nas estruturas produtivas dos países. A terceirização e o crescimento do setor informal refletem-se no mercado de trabalho, no acesso aos alimentos e, por conseguinte, nas condições de saúde e nutrição das populações.

A urbanização é um outro conceito chave dessa análise. $\mathrm{O}$ fenômeno intitulado Transição Nutricional ${ }^{3}$ ancora as mudanças no modo de viver das populações nos últimos 30 anos, a partir da urbanização e globalização, que operou mudanças importantes em termos de padrões alimentares e gasto energético nas sociedades ocidentais.

Neste sentido, Santos (2005, p. 9) destaca uma reflexão interessante sobre a urbanização brasileira. A urbanização brasileira torna-se praticamente generalizada a partir do terceiro terço do século XX, uma

\footnotetext{
2 É um programa de transferência de renda cujo objetivo é combater a fome e a pobreza associando, ao recebimento do benefício financeiro, o acesso aos direitos sociais básicos - saúde, alimentação, educação e assistência social. Famílias extremamente pobres recebem o benefício básico de R\$ 6o, oo, mais R\$ 18,oo por criança até 15 anos, até no máximo 114,oo por família. Famílias pobres recebem R\$ 18,oo por criança, até o limite de três benefícios. O benefício é transferido prioritariamente para mulheres/mães, por intermédio de um cartão magnético único para famílias incluídas no Cadastro Único do Governo Federal. A meta do programa é atingir todas as famílias em situação de insegurança alimentar no Brasil até 2007.

3 As mudanças econômicas, sociais e demográficas ocorridas nas últimas décadas, em decorrência da crescente modernização e urbanização, provocaram alterações no estilo de vida da população e em particular nos hábitos alimentares. Tais modificações resultaram em alterações dos padrões de estado nutricional, com um aumento da prevalência de sobrepeso e obesidade e diminuição da ocorrência de desnutrição, caracterizando assim a transição nutricional (Monteiro, 20oo).
} 
evolução quase contemporânea da fase atual de macrourbanização e metropolização. "O turbilhão demográfico e a terceirização são fatos notáveis”. Mais que um Brasil urbano e rural, há hoje um Brasil urbano (agrícola) e um Brasil agrícola (urbano). O perfil urbano assume uma complexidade com a metrópole como onipresença. Neste paralelo, a expansão do consumo de alimentos, de medicamentos, de livros e materiais escolares, e de serviços em geral torna-se diretamente proporcional ao consumo de eletrodomésticos, de viagens, de idéias, de informações e de esperanças, sempre na busca de uma resposta concentrada que amplia cada vez mais a urbanização, criando-se ciclicamente mais formas de necessidades, desejos e consumo.

Esta "nova" realidade tem produzido diferentes formas de viver, adoecer e morrer nas populações. Mundialmente, as distribuições das principais causas de mortalidade e morbidade mudaram profundamente, incluindo países desenvolvidos e em desenvolvimento. As prevalências de DCNT têm aumentado rapidamente e, em 2001, foram responsáveis por $47 \%$ da carga mundial de mortalidade. Considerando que o crescimento previsto dessa carga pode ser evitado por meio de medidas de prevenção, seu controle constitui-se num desafio muito importante para saúde pública (WHO, 2002, 2003).

O informe sobre a saúde no mundo da Organização Mundial da Saúde - OMS expõe as circunstâncias das causas e, na maioria dos países, uns poucos fatores de risco são responsáveis em grande parte pela morbidade e mortalidade. No caso das doenças não-transmissíveis, os fatores de risco mais importantes são: hipertensão arterial, hipercolesterolemia, pouca ingestão de frutas e hortaliças, excesso de peso ou obesidade, falta de atividade física e consumo de tabaco. Cinco desses fatores de risco estão estreitamente associados à má alimentação e à falta de atividade física (WHO, 2002, 2003).

O tipo de alimento predominantemente consumido pela população brasileira é industrializado. Segundo última Pesquisa de Orçamento Familiar POF (2003) do IBGE, os gastos com alimentação ocupam o segundo lugar na participação da despesa total familiar, representando, na média nacional, 21\% dos gastos com despesas de consumo e $17 \%$ dos gastos totais das famílias (FIBGE, 2004).
Esse perfil de despesas com alimentação indica mudanças no comportamento das famílias brasileiras em relação ao local de realização das principais refeições. Quase um quarto (24\%) da despesa média mensal familiar com alimentação é destinado a refeições fora de casa. Esse percentual na área urbana (26\%) é o dobro do encontrado na área rural (13\%). Tais resultados confirmam a tendência do brasileiro em fazer suas refeições fora de casa, o que ressalta a importância da promoção da alimentação saudável nas instituições e estabelecimentos públicos e comerciais do ramo da alimentação. $O$ consumo de alimentos preparados consumidos nos domicílios da zona urbana é aproximadamente $358 \%$ mais alto do que nos domicílios da zona rural (Brasil, 2004).

Nota-se, ainda, que alimentos tradicionais na dieta do brasileiro, como o arroz e o feijão, perdem importância no período, enquanto o consumo de produtos industrializados, como biscoitos e refrigerantes, aumenta em 400\%. Um dos efeitos da globalização é a busca pelo pensamento único e neste paralelo um "comer formatado" se coloca como modelo de modernidade. 0 comer formatado significa que a escolha do alimento traz consigo representações sociais e a busca de um perfil a ser alcançado. Mostra-se capaz de criar imagens e códigos decifráveis por grupos, sugerindo e encadeando comportamentos.

Nesta reflexão, as relações entre o fast foods e o processo de globalização precisam ser analisadas, pois sinalizam uma dinâmica social contemporânea importante. A estandardização de certas dimensões das práticas e do comportamento alimentar facilitam as mudanças na alimentação, que vão sendo incorporadas como parte do modo de vida. 0 poder aquisitivo, a publicidade e a praticidade exercem pressão sobre as práticas alimentares que se tornam permeáveis a mudanças, representadas pela incorporação de novos alimentos, formas de preparo, compra e consumo. Os elementos que compõe as escolhas alimentares se alteram e definem um outro padrão alimentar (Ortigoza, 1997; Garcia, 2003).

Essas considerações sobre a disponibilidade domiciliar de alimentos adquiridos pelas famílias brasileiras confirmam que as mudanças de padrão alimentar no país têm sido, de modo geral, favoráveis do ponto de vista dos problemas associados à desnutrição (au- 
mento na disponibilidade de calorias per capita e da participação de alimentos de origem animal na alimentação) e desfavoráveis no que se refere à obesidade e às demais DCNT (aumento da participação na alimentação de gorduras em geral, gorduras de origem animal e açúcar e diminuição com relação a cereais, leguminosas e frutas, verduras e legumes) (Pinheiro, 2005).

Em síntese, os dados recentes da POF verificaram um aumento expressivo da obesidade entre homens em geral; e entre mulheres uma acentuação somente na população de baixa renda, principalmente no meio rural. Esses dados sinalizam para uma mudança no perfil epidemiológico nutricional da população brasileira; contudo, não refletem melhoria nesse perfil. Pelo contrário, tais evidências deixam claro que a natureza da problemática alimentar e nutricional requer ações para tratar à má-nutrição em sua globalidade, seja manifestada pela carência; seja resultante do excesso de consumo energético e inadequação alimen$\operatorname{tar}$ (Brasil, 2004; Pinheiro, 2005).

Outro ponto relevante é que os dados desmistificam, de uma vez por todas, que excesso de peso e obesidade são condições privativas de populações economicamente mais favoráveis. Os estratos mais pobres são duplamente afetados, pois têm o risco à saúde aumentado uma vez que convivem, muitas vezes sob o mesmo teto, com o sobrepeso e a obesidade e com a desnutrição e o baixo peso - como manifestações biológicas da fome (Brasil, 2004).

No contexto analisado destaca-se que o Estado, ao assumir a responsabilidade de formulador de políticas sociais, passa a ser uma "arena de lutas por acesso a riqueza social” (Silva, 1997, p. 190), pois a políticas públicas envolvem conflitos de interesses entre as classes sociais e as respostas do Estado para as questões demandadas. Os sujeitos operam de forma relacional no espaço do Estado e/ou sociedade, mas com a ascensão do neoliberalismo, a esfera do mercado, que representa a dimensão econômica, passa a ter um papel estratégico. O jogo de interesses se expressa tanto no poder legislativo (lobbys das indústrias de alimentos) quanto no poder executivo (Ministérios) e tem no contexto institucional as agências reguladoras como interlocutores ou agentes de fiscalização. Neste formato, no âmbito da produção de alimentos, desde 1999, a Agência Nacional de Vigilância Sanitá- ria (ANVISA) e o Ministério de Agricultura, Pecuária e Abastecimento (MAPA) representam o Estado na relação da sociedade com o mercado.

As mudanças na relação do Estado, sociedade civil e mercado têm trazido uma série de conseqüências sociais adversas no campo da alimentação e nutrição. A reflexão sobre o papel da política social no momento atual é de crucial importância. De acordo com Demo (2002, p. 29), “...é imprescindivel rever o papel do Estado e do mercado, não para eliminar instâncias que são históricos - estruturais, mas para qualificálas. O mercado não pode ser capitalista, nem o Estado sucursal do mercado." E este questionamento em si não pode implicar em imobilismo, pois é necessário dar conta da vida e da sobrevivência no contexto concreto da sociedade atual. A possibilidade de emergência de novo paradigma de política social pressupõe a reconquista da emancipação como diretriz crucial, de maneira articulada com a abordagem de direitos humanos.

Numa perspectiva dialética, tanto o Estado quanto o mercado são fenômenos antigos. Existiram em todas as sociedades descritas e conhecidas e possuem na atualidade formatos bem mais definidos do que em épocas anteriores. Entretanto, não se pode confundir a noção de mercado como fenômeno histórico-estrutural com os mercados neoliberais. 0 primeiro é circunstancial e o segundo é constante em todas as sociedades. Nesta mesma lógica, o Estado (também presente histórico-estruturalmente em todas as sociedades) pode adquirir traços neoliberais ou não. Pode garantir a compreensão de que saúde e educação são direitos de todos e não se compra nem se vende, pois não são mercadorias ou, ao contrário, na lógica da economia de mercado neoliberal, pode "lotear" espaços públicos como escolas e hospitais para serem apropriados pela iniciativa privada e por ela explorados, para o acesso de alguns poucos (Demo, 2005).

Segundo Pedro Demo (2005), nem mercado nem Estado devem ser divinos ou satânicos, ambos são histórico-estruturais, porém devem, num contexto capitalista, ser democraticamente controlados e utilizados para o bem-estar. Não parece ser possível uma sociedade sem Estado ou mercado, porém pode (e deve) ser possível uma sociedade capaz de controlá-los de maneira que respondam ao coletivo e busquem justiça social. 
Medidas de Regulamentação: um apoio para a promoção da alimentação saudável no contexto da PNAN

Neste complexo conjunto de elementos que busca articular análises e conceitos oriundos das ciências sociais e da saúde, não se pretende fazer uma profunda discussão teórico-conceitual, mas basicamente levantar reflexões sobre as nuances subjetivas, e geralmente não aparentes, do processo de mudanças do perfil nutricional da população brasileira.

0 que se pretende problematizar aqui é: até que ponto os objetivos e interesses de mercado e Estado não se antagonizam ou se opõem? Tendo como exemplo a questão da obesidade e seu alarmante aumento, em que medida o mercado está disposto a compartilhar esta responsabilidade? Em que medida aceita abrir mão das estratégias de lucro e de marketing para promover uma alimentação mais saudável em parceria com o Estado?

Entende-se que a pretensa responsabilidade compartilhada (recomendada pela cartilha neoliberal) só é possível na medida em que os papéis de todos os atores envolvidos estão definidos de forma igualitária. Na perspectiva de um Estado mínimo para a defesa dos direitos sociais e interesses da sociedade, como se sustenta a proposta de "responsabilidade compartilhada"? Para um mercado que reivindica autonomia para livre relação com a sociedade, qual a possibilidade de "com-partilhar"? Se o papel do Estado e do mercado perante a sociedade não é de neutralidade, como negar a defesa de interesses distintos neste processo?

No âmbito da PNAN algumas medidas ilustram este cenário de "luta de interesses" entre mercado, sociedade e Estado na arena política. A primeira questão está presente no Guia Alimentar para a População Brasileira (Brasil, 2005) e coloca a necessidade de melhora do padrão de composição dos alimentos industrializados, com redução dos níveis de sódio, açúcar e gordura trans (hidrogenada), como questão-chave para o controle e prevenção de doenças crônicas não-transmissíveis - como obesidade, hipertensão, osteoporose e diabetes. Investimentos em tecnologias que preservem a integridade dos alimentos, o mais próximo do in natura possível, são fundamentais. E esta demanda não pode ser confundida com o fomento a investimentos em "novos" alimentos e produtos intitulados como funcionais especiais, light e diet. Ressalvado os benefícios que esses alimentos podem trazer a um grupo de pessoas, que requerem uma alimentação diferenciada, não podem ser o eixo de uma política pública que preconiza a alimentação saudável acessível para todos.

Entende-se alimentação saudável como um direito humano que contemple um padrão alimentar adequado às necessidades biológicas, culturais, sociais e econômicas dos indivíduos, respeitando os princípios de acessibilidade físico e financeiro, sabor, variedade, cor, harmonia e segurança sanitária, com ênfase em práticas alimentares que assumam os significados simbólico-cultural da comida nas relações sociais das populações (Pinheiro, 2005).

A segunda questão é a necessidade de instituir medidas de regulamentação dos processos de comercialização de alimentos. No Brasil, as medidas de regulamentação se apresentam sob dois aspectos principais: o primeiro em relação ao disciplinamento da publicidade de alimentos voltados para o público infantil e o segundo sobre a normatização do comércio de alimentos em lanchonetes escolares.

As medidas de regulamentação de comércio de alimentos têm sido formuladas a partir dos estados ou municípios, ou seja, são leis locais que procuram respeitar as diversidades culturais relativas à alimentação e diferenças regionais existentes no Brasil. O processo de discussão para formulação de uma lei de regulamentação de publicidade e práticas de marketing para o público infantil assumiu um caráter federal. Os principais fatores de risco para a saúde têm similaridade nacional no atual contexto globalizado de produção de desejos e necessidades.

A proposta de formulação de leis e regulamentações relacionadas ao tema da alimentação surge a partir do Código Internacional de Comercialização de Substitutos do Leite Materno, aprovado pela Organização Mundial da Saúde, em 1981. No Brasil, a Política Nacional de Aleitamento Materno (com 25 anos de existência) tem como um dos principais avanços a aprovação da Lei Federal $n^{0}$. 11.265/2006 (Brasil, 2006a), que regulamenta a propaganda abusiva dos produtos que interferem na amamentação. A lei foi elaborada com base na Norma Brasileira de Comercialização de Ali- 
mentos para Lactentes e Criança de Primeira Infância, Bicos, Chupetas e Mamadeiras (NBCAL), constituída pela Portaria MS nº. 2.051/o1 e pelas resoluções da Agência Nacional de Vigilância Sanitária (ANVISA) $n^{0} \cdot 221$ e $n^{0} \cdot$ 222/o2. A lei prevê autuação e punição para estabelecimentos de saúde e empresas que não se enquadrarem nos dispositivos da legislação. A transformação da estrutura legal da NBCAL em lei federal representa um marco importante na proteção da amamentação contra as estratégias de marketing no Brasil.

O Programa Nacional de Incentivo ao Aleitamento Materno (PNIAM) foi criado em 1981, sob a coordenação do Instituto Nacional de Alimentação e Nutrição, com o apoio de vários segmentos da sociedade civil organizada (Monteiro, 20o6). Desde então, o aleitamento materno passou a ser uma prioridade da política pública de saúde, sempre incluído entre os elementos a serem trabalhados para a redução da mortalidade infantil.

Outra medida internacional similar da OMS, aprovada na sua $5^{\mathrm{a}}$. Assembléia Mundial de Saúde, em 2003 , foi a ratificação da Convenção Quadro, que dispõe de um elenco de metas para a redução do consumo de tabaco. No Brasil, as discussões foram bastante polêmicas, uma vez que, neste cenário de economia de mercado, interesses econômicos tendem a prevalecer sobre os interesses sociais. Contudo, um forte movimento de apoio redundou na assinatura do Brasil como signatário. Ao ratificar essa Convenção, o Estado brasileiro assume o compromisso da construção de uma agenda com vistas à implementação de medidas legislativas, executivas, administrativas e/ou outras medidas adequadas para prevenir e reduzir o consumo de tabaco, a dependência da nicotina e a exposição à fumaça do tabaco, além de cooperar com outros Estados Membros na elaboração de políticas, protegendo estas dos interesses comerciais da indústria do tabaco (Brasil, 2003).

Ao longo das últimas décadas, o Brasil apresentou indicadores favoráveis relativos à cessação de fumantes. O consumo per capita anual de cigarros também tem demonstrado que o consumo / aquisição de cigarros vem se reduzindo no Brasil. Entre 1980 e 2001, o consumo per capita total de cigarros apresentou uma redução de aproximadamente 38\%, passando de 1937 unidades, em 1980, para 1194 unidades, em 2001, in- cluindo as estimativas de consumo de cigarros provenientes do mercado ilegal (Brasil, 2003).

No Brasil, ainda não existe legislação específica de regulamentação de propaganda comercial de alimentos. Há um projeto de lei no Senado Federal que visa regular propagandas (PLS n. 25, 2003), porém o cenário epidemiológico atual provocou a ANVISA na formação de um Grupo de Trabalho (GT) para discutir a elaboração e aprovação de regulamento sobre propaganda, publicidade, promoção e informação, e outras práticas cujo objeto seja a divulgação, promoção ou comercialização de alimentos, de produção nacional ou estrangeira, quaisquer que sejam as formas e meios de sua veiculação, incluindo as transmitidas no decorrer da programação normal das emissoras de rádio e televisão (Delgado, 2005).

Esse GT envolveu representantes do mercado publicitário, como o CONAR (Conselho Nacional de AutoRegulamentação Publicitária), fabricantes como a ABIA (Associação Brasileira das Indústrias da Alimentação) e do Estado, como o Ministério da Saúde; Ministério da Agricultura, Pecuária e Abastecimento; Ministério Público da União; Universidades e representantes do Congresso Nacional. O propósito da discussão foi estruturar proposta para coibir práticas abusivas de publicidade e marketing que auxiliem o aumento de doenças crônicas não-transmissíveis e especialmente o excesso de peso. Estudos científicos têm comprovado uma associação positiva entre horas de televisão e desenvolvimento de obesidade infantil (Borzekowski e Robinson, 2001). A proposição foi submetida ao processo de Consulta Pública $n^{\circ} .84$, de 16 de novembro de 2005 , da ANVISA, e encontra-se no aguardo de realização de audiência pública.

A motivação e justificativa para a criação das regulamentações é a necessidade de resgate do papel do Estado como mediador das relações entre mercado e sociedade. Assumir o papel de apoio, proteção e promoção da saúde é fundamental para resgatar os efeitos negativos da ausência de políticas públicas de promoção da saúde, potencializados pela ascensão do neoliberalismo e da globalização. O Brasil aprovou, em 2006, a Política Nacional de Promoção da Saúde, na portaria 687 de 30/o3/20o6 DOU 31/o3/2006 (Brasil, 2006b).

Medidas de regulamentação têm sido implementadas por outros países. Em termos de natureza de in- 
tervenção, um estudo organizado pela Organização Mundial da Saúde (OMS) definiu duas categorias: governamentais (Estado) e auto-regulamentações (mercado). Em muitos casos, ambas as formas de regulamentação coexistem. 0 princípio que determina várias regulamentações é o de que a propaganda não deveria ser fraudulenta ou enganosa. A maioria das regulamentações nacionais reconhece as crianças como um grupo que precisa de especial consideração e também especifica que propaganda não deve ser nociva ou exploradora de sua ingenuidade (Hawkes, 2004).

As regulamentações governamentais (Estado) usualmente são leis nacionais e estatutos / códigos de proteção do consumidor. Em relação a crianças, proíbem a exploração de credulidade; prezam pelo zelo à saúde física, mental e moral; impedem a discriminação ou indução a sentimentos de inferioridade e também a indução a formas de persuasão junto aos pais para a aquisição dos produtos anunciados. Uma forma bastante utilizada tem sido a limitação de tempo dos anúncios ou limitação do conteúdo a ser anunciado.

A publicidade televisiva é talvez a maneira mais popular no mundo todo de promover produtos alimentícios e bebidas e, conseqüentemente, tem sido objeto de maior debate em termos de efeitos em crianças, que qualquer outra prática de marketing. Também é a mais amplamente regulamentada, de acordo com estudo da OMS, em que $85 \%$ dos 73 países pesquisados tinham alguma forma de regulamentação através de publicidade na televisão direcionada para crianças, e quase a metade (44\%) tinha restrições específicas com relação ao tempo e ao conteúdo das propagandas na televisão (Hawkes, 2004).

Já as auto-regulamentações (mercado) são baseadas na formulação de estatutos pelo próprio setor regulado (publicidade e marketing) com ênfase em diretrizes éticas, auto-definidas. Um dos pressupostos defendidos é a legalidade, decência e honestidade dos anúncios (Hawkes, 2004).

Suécia, Canadá e Noruega apresentam medidas de regulação que proíbem qualquer forma de publicidade e práticas de marketing voltadas para o público infantil até 12 anos. Suécia e Noruega são países escandinavos que, na análise das bases do modelo de welfare state, parecem ter aceitado o fato de que desigualdades maiores são inevitáveis, mas procuram garantir que não ocorra concentração dessas desigualdades em nenhum estrato da sociedade, ou que não se tornem permanentes na vida das pessoas. Para tal, utiliza-se da estratégia de "investimento social" (Esping - Andersen, 1995). O papel do Estado na proteção da saúde é claro e bem definido. Toma para si a responsabilidade do apoio para regulamentações provenientes de leis e políticas públicas.

\section{Considerações Finais: uma chamada para reflexão}

A Política Nacional de Alimentação e Nutrição é uma política social de cunho intersetorial que requer um olhar inter e trans-disciplinar no contexto da gestão pública. Não há formas de avançar nessa implementação sem definir e pactuar papéis relativos à totalidade das esferas envolvidas nesse processo: Estado, sociedade e mercado.

Porém, a concretização da intersetorialidade na gestão de políticas sociais precisa incorporar não apenas a compreensão compartilhada sobre finalidades, objetivos, ações e indicadores de políticas, programas ou projetos, mas também práticas sociais articuladas que impactem positivamente no modo de viver das populações. A ação intersetorial não se esgota no âmbito de uma política social específica, mas sim num conjunto de políticas que busquem alternativas para lidar com a complexidade e amplitude dos problemas sociais, como é o caso da obesidade (Junqueira, 2004).

Não podemos esquecer que diferentes interesses impulsionam os papéis do Estado e do mercado nessa temática. 0 novo paradigma da saúde é: como organizar medidas capazes de promover a saúde e prevenir doenças, a fim de garantir modos de viver mais saudáveis e também diminuir os gastos relativos ao setor saúde com as taxas de morbimortalidade por DCNT? E a demanda que se coloca para o mercado é: como se adequar às mudanças necessárias para a produção de alimentos menos processados, acessíveis do ponto de vista financeiro e com teores reduzidos de sal, açúcar e gorduras em geral, sem abrir mão do lucro esperado?

Os pressupostos da promoção da saúde indicam um caminho para a melhoria das condições de vida e saúde por meio do exercício da cidadania. E para tal, é preciso ações generalizadas que provoquem transformações em todas as pessoas, para que estas possam tomar o controle das situações a que são submetidas 
sentindo-se, portanto, sujeitos de direitos e cidadãos de fato. Perguntas, como em que medida a sociedade abre mão de benefícios individuais em detrimento de direitos sociais para a construção de um bem-estar coletivo?, são questões-chaves para inserção nos debates contemporâneos.

No contexto de medidas de regulamentação, a defesa da liberdade de escolha individual é um argumento hegemônico nos debates dos meios de comunicação brasileiros com a sociedade, sob a tutela da defesa da democracia. É preciso ter coragem para perceber que a prerrogativa do poder de escolha entre este ou aquele alimento não é aleatória. Os interesses do capital também influenciam o atual padrão alimentar. Essa "liberdade" é ilusória na medida em que o acesso ao conjunto da totalidade de alimentos disponíveis para consumo é impedido.

Nesse debate com a sociedade, a teoria da alienação em Marx, apresentada por Isteván Mézáros, também pode auxiliar na reflexão. Entendendo a alienação como "a perda do controle sobre as atividades humanas que a população deveria controlar... o sistema social ao invés de ser controlado pela sociedade fica alienado, ou seja, fora de controle. A alienação leva a ilusão de ser a ordem certa das coisas e desta forma alimenta a ideologia dominante"(Mézaros, 2006, p. 2). Se somarmos a isso o fortalecimento de valores neoliberais, como a competição e o individualismo, visualizamos perfeitamente o tamanho do desafio que se coloca como gargalo desse processo. Numa perspectiva histórico-cultural, esses valores "impregnam" as relações sociais e transformam conquistas coletivas em uma mera "invasão de privacidade" ou violação do "direito individual de escolha". Com isso, a compreensão coletiva de força política e a pressão social se enfraquecem ainda mais, resultando numa atomização completa das vontades.

O papel da ANVISA, como representante do Estado, precisa ser ousado e enfrentar os desmandos do capital em defesa dos direitos sociais para proteção da saúde da população. Medidas de regulamentação, se democraticamente construídas, devidamente fiscalizadas pela sociedade e Estado e assumidas pelo mercado, podem exercer impacto positivo sobre os resultados esperados junto a programas, projetos e ações que busquem apoiar a implementação da PNAN.

\section{Referências}

ANDERSON, P. Balanço do neoliberalismo. In: SADER, E.; GENTILLI, P. (Org.). Pós-neoliberalismo: as políticas sociais e o Estado democrático. Rio de Janeiro: Paz e Terra, 1995. p. o9-34.

BERLINGUER, E. R. Política social no capitalismo tardio. São Paulo: Cortez, 2002.

BORZEKOWSKI, D. L.; ROBINSON, T. N. The 30second eddect: an experiment revealing the impact of television commercials on food preference of preschoolers. Journal of the American Dietetic Association, n. 101, p. 42-46, 2001.

BRASIL. Ministério da Saúde. Instituto Nacional do Câncer. Programa Nacional de Controle do Tabagismo e outros fatores de risco de câncer: modelo lógico e avaliação. 2. ed. Rio de Janeiro, 2003.

BRASIL. Lei n ${ }^{0} 11.265$, de 3 de janeiro de 2006. Regulamenta a comercialização de alimentos para lactentes e crianças de primeira infância e também a de produtos de puericultura correlatos. Diário Oficial [da] Republica Federativa do Brasil, Brasília, DF, 4 jan. 20o6a.p. 1

BRASIL. Ministério da Saúde. Portaria n 687, de 30 de março de 2006. Aprova a Política de Promoção da Saúde. Diário Oficial [da] República Federativa do Brasil. Brasília, DF, 31 mar. 20o6b. Seção 1, p. 63.

BRASIL. Conselho Nacional de Segurança Alimentar e Nutricional. Princípios e diretrizes de uma Política de Segurança Alimentar e Nutricional: textos de referência II CSAN. Brasília, DF, 2004. Disponível em: <https://www.planalto.gov.br/Consea/static/ documentos/Outros/LivroConsea_Documento Referencia.pdf $>$. Acesso em: 15 out. 2004.

BRASIL. Ministério da Saúde. Guia alimentar da população brasileira: promovendo uma alimentação saudável. Brasília, DF, 2005a.

BRASIL. Ministério da Saúde. Política Nacional de Alimentação e Nutrição. Brasília, DF, 1999.

BRASIL. Ministério da Saúde. Considerações do Ministério da Saúde sobre a Pesquisa de Orçamento Familiar 2002-2003. Brasília, DF, 2005b. (Textos para discussão). 
BURLANDY, L. O. Comunidade solidária e os programas de alimentação e nutrição: focalização e parcerias. 2003. Tese (Doutorado em Saúde Pública) Fiocruz, Rio de Janeiro, 2003.

BYDLOWSKI, C. R; WESTPHAL, M. F.; PEREIRA, I. M. T. B. Promoção da saúde: porque sim e porque não! Saúde e Sociedade, São Paulo, v.13, n. 1, p. 14-24, 2004.

CUNHA, E. P.; CUNHA, E. S. M. Políticas públicas sociais. In: CARVALHO, A. et al (Org.). Políticas públicas. Belo Horizonte: UFMG: PROEX, 2003. p. 1125 .

DEMO, P. Santo estado, maldito mercado: de certas esquerdas que são direitas. Sociedade e Estado, Brasília, DF, v. 20, n. 2, p. 451-476, 2005.

DEMO, P. Novos paradigmas em política social. In: CARVALHO, D. B. B.; DEMO, P.; SOUSA, N. H. B. (Org.). Novos paradigmas da política social. Brasília, DF: UnB, Programa de Pós-Graduação em Política Social, Departamento de Serviço Social, 2002. p. 13 - 50.

ESPING-ANDERSEN, G. O futuro do Welfare State na nova ordem mundial. Revista Lua Nova/CEDEC, São Paulo, n. 35, p. 85 - 116, 1995.

FAGNANI, E. Política social e pactos conservadores no Brasil: 1964-92. Cadernos FUNDAP, São Paulo, n. 21, p. 59-102, 1997.

FUNDAÇÃO INSTITUTO BRASILEIRO DE GEOGRAFIA E PESQUISA. Pesquisa de Orçamentos Familiares 2002-2003: analise da disponibilidade domiciliar de alimentos e de estado nutricional Brasil. Rio de Janeiro, 2004. Relatório final.

GARCIA, R. W. Reflexos da globalização na cultura alimentar. Revista de Nutrição, Campinas, v. 16, n. 4, p. 483-492, 2003 .

HAWKES, C. Marketing food to children: the global regulatory. Genebra: World Health Organization, 2004.

JUNQUEIRA, L. A. P. A gestão intersetorial das políticas sociais e o terceiro setor. Saúde e Sociedade, São Paulo, v. 13, n. 1, p. 25-36, 2004.

LEFÈVRE, F. Mitologia sanitária: saúde, doença, mídia e linguagem. São Paulo: Ed. Universidade de São Paulo, 1999.
MÉZAROS, I. Entrevista: é preciso recuperar o sentido da educação. Jornal Brasil de Fato, São Paulo, ano 4, n.169, p. 8, 29 maio 2006.

MONTEIRO, C. A. Velhos e novos males da saúde no Brasil: a evolução do país e suas doenças. São Paulo: Hucitec, 2000.

MONTEIRO, R. Norma brasileira de comercialização de alimentos para lactentes e crianças de primeira infância: histórico, limitações e perspectivas. Revista Panamericana de Saúde Publica Washington, v. 19, n. 5, p. 354-362, 2006.

MOZART, J. O. O financiamento da área social e do sistema único de saúde Brasil. Disponível em: <http:/ /www.datasus.gov.br/cns/temas/Financiamento/ FINANCIAMENTO-CADERNO DE TEXTOS.html >. Acesso em: 1 jul. 2005. (Temas em debate).

ORTIGOZA, S. A. O fast food e a mundialização do gosto. Revista Cadernos de Debate, Campinas, v. 5, p. 21-45, 1997.

PELIANO, A. M. P. A Política Nacional de Alimentação e Nutrição. Cadernos do NESP, Brasília, DF, v. 1, n. 2, p. 41-48, 1998.

PEREIRA, P. A. P. Concepções e propostas de políticas sociais em curso: tendências, perspectivas e conseqüências. Brasília, DF: NEPPOS, CEAM - UnB, 1994 .

PEREIRA, P. A. P. Política social, cidadania e neoliberalismo: reflexão sobre a experiência brasileira. In: CARVALHO, D. B. B.; DEMO, P.; SOUSA, N. H. B. (Org.). Novos paradigmas da política social. Brasília, DF: UnB, Programa de Pós-Graduação Política Social, Departamento de Serviço Social, 2002. p. $253-273$.

PEREIRA, P. A. P. A metamorfose da questão social e reestruturação das políticas sociais. In: Capacitação em serviço social e política social: módulo 1: política social. Brasília, DF: UnB, 1999. p. 45-58.

PESSANHA, L. D. R. A experiência brasileira em políticas públicas para a garantia do direito ao alimento. Rio de Janeiro: Escola Nacional de Ciências Estatísticas, 2002. (Textos para discussão, 5). 
PINHEIRO, A. R. O. A alimentação saudável e a promoção da saúde no contexto da segurança alimentar e nutricional. Saúde em Debate, São Paulo, v. 29, n. 70, p. 125-139, 2005.

PIRES, M. F.; REIS, J. R. T. Globalização, neoliberalismo e universidade: algumas considerações. Revista Interface: comunicação, saúde e educação, Botucatu, v. 3, n. 4, p. 29-39, 1999.

POLANYI, K. A grande transformação: as origens da nossa época. 2. ed. Rio de Janeiro: Elsevier, 2000.

SANTOS, M. A urbanização brasileira. 5. ed. São Paulo: EdUSP, 2005.

SETTI, G. A. M. A hegemonia neoliberal e o capitalismo contemporâneo. Revista Urutágua Acadêmica Multidisciplinar, Maringá, n. 5, 2004. Disponível em: < http://www.urutagua.uem.br/oo5/ o4eco_setti.htm.>. Acesso em: 14 maio 2006.
SILVA, A. A política social e a política econômica. Revista Serviço Social e Sociedade, São Paulo, n. 53, p. 189-191, 1997.

SILVA, A. A. As relações do estado - sociedade e as formas de regulação social. In: Capacitação em serviço social e política social: módulo 2: política social. Brasília, DF: UnB, 1999. p. 55 - 71.

WORLD HEALTH ORGANIZATION. World Health Report. Genebra, 2002.

WORLD HEALTH ORGANIZATION. Diet, nutrition and the prevention of chronic diseases. Geneva, 2003. (WHO Technical Report Series, 916). 